\title{
ICTERUS GRAVIS NEONATORUM WITH ERYTHROBLASTOSIS
}

\author{
BY \\ HELEN MCKINLEY, M.D.
}

Erythroblastosis means a widespread extra-medullary haematopoiesis evident chiefly in liver and spleen, but seen also in kidneys, pancreas, suprarenals and various other organs. It can be recognized only by histological examination of the organs. The amount and extent of the erythropoietic foci are comparable to the picture observed in a twenty to twenty-four weeks old foetus. Erythroblastaemia means the presence in the peripheral circulation of a greater number of nucleated red blood cells than the physiological maximum for the age. In the majority of full-term normal new-born infants the nucleated red cells, consisting of erythroblasts, normoblasts and megaloblasts, vary between five and ten per 100 leucocytes or about 1000 per c.mm. of blood. In exceptional instances they may reach twenty-five to thirty-five per 100 leucocytes. In the case of premature infants these figures are somewhat higher. Disappearing rapidly, the nucleated red celis are usually absent from the blood by the second or third day, and are seldom seen after the fifth day of life. In erythroblastosis this process requires about three weeks. Though the continued presence of nucleated red cells is very suggestive that a condition of erythroblastosis exists, a diagnosis should not be made unless other distinctive signs are present also.

Clinical features. There are three closely-related symptom-complexes which are dependent on the same underlying pathological process of erythroblastosis. They are: (1) universal oedema of the foetus: (2) anaemia of the new-born: (3) icterus gravis neonatorum. This paper will consider only the symptom-complex due to the disturbance of the haematopoietic system in which icterus is the most striking presenting sign, namely icterus gravis neonatorum with erythroblastosis.

The criteria for the diagnosis of this condition, as outlined in 1932 by Blackfan, Diamond and Baty of Boston are: (1) familial incidence of early and severe jaundice, (2) anaemia, (3) abnormally large numbers of nucleated erythrocytes in the blood, (4) enlargement of the liver and spleen, and (5) haematopoiesis to an extraordinary degree in the extramedullary sites. Since the first and second child in a family are frequently unaffected, and because sporadic cases frequently occur, a positive family history should not be a necessary qualification. The syndrome of icterus gravis is characteristic. It is often familial, and there may be a history that other members of the family died of 
severe icterus or were born dead with oedema of the new-born. The infant is either born jaundiced, in which case the amniotic fluid and vernix may be a deep yellow, or jaundice develops within the first twenty-four hours. This is in contradistinction to physiological icterus neonatorum, which makes its appearance on the second or third day of life. The occurrence of jaundice in the first twelve hours should always cause concern. The liver and spleen are invariably enlarged and petechial or purpuric areas frequently seen. Oedema is occasionally present. Anaemia, masked by an increasing jaundice, is a rapid development. In some instances the red count may drop by as much as a million cells and the haemoglobin by 50 per cent. in twenty-four hours. Haemolytic hypochromic anaemia is possibly as characteristic of erythroblastosis as is erythroblastaemia and allows early diagnosis to be made. Cases of icterus gravis with marked erythroblastaemia may show a rapid diminution or even disappearance of abnormal red cells from the peripheral blood. This applies to untreated as well as to transfused infants. The white blood-cell count is usually increased. Infants with icterus gravis are frequently difficult to resuscitate at birth, exhibit a peculiar somnolence, and may have mild or even severe convulsions. Coincident intracranial haemorrhage is a fairly common occurrence.

Various diagnoses were made on admission, including septicaemia, haemolytic anaemia, haemorrhagic disease of the new-born, intracranial haemorrhage, suprarenal haemorrhage, icterus neonatorum, haemolytic jaundice, congenital lues and congenital atresia of the bile-ducts.

The etiological factors concerned in this disease are a much debated question. The Boston group has stated that the disease is a disturbance of the metabolism of the haematopoietic system resulting in a failure of maturation of erythrocytes or in an overgrowth of immature forms. The view held by the English group is that the embryonic haematopoiesis is a symptom and not a cause of the disease; a response to an increased demand for red cells as a result of excessive haemolysis. Neither theory explains all the facts. The other signs of the disease complex, the anaemia, haemosiderosis, oedema and icterus may all be related to the dysfunction of erythrocyte production. The icterus is primarily of a haemolytic type, the result of the destruction of red blood-cells. The continuation of this process may so overburden the liver cells of the young organism that functional inefficiency may occur and a greater degree of icterus result.

The prognosis formerly has been considered very grave. However, many infants undoubtedly' suffer from icterus gravis in a mild form and recover without treatment. Of the more seriously affected group, about half died, and of those surviving, about two-thirds exhibited at a later date sequelae referable to the central nervous system as a result of jaundice of the nuclear masses of the brain, or 'kernikterus'. This nuclear icterus is responsible for a certain proportion of deaths occurring before the fifth day and may manifest itself in respiratory paralysis, convulsions, drowsiness or head retraction. The four cardinal signs of the late syndrome of nuclear jaundice are: (1) choreo-athetosis; (2) extra-pyramidal spasticity; (3) opisthotonos; (4) mental deficiency.

The pathological picture shows the lesions to be limited to the striatopallidal portions of the brain, which during the acute phase of the disease are stained 
with bile pigment and show evidence of cell destruction. The late lesions show evidence of this previous destruction of nerve elements, as demonstrated by loss of nerve cells, demyelination and glial proliferation.

The pathogenesis remains obscure. It is supposed that, following some injury, the nerve cells and myelin sheaths are subsequently stained with bile pigments carried to them by the blood in the same manner as any intravital dye will localize in zones of injury and will leave unstained tissues which are not damaged. The nature of the injurious factor is purely speculative at present, but a sub-clinical type of intrauterine infection has been mentioned. The infant may have clinical signs of ' kernikterus' with no post-mortem evidence, and, conversely, stained basal nuclei have been reported at autopsy when there was no evidence during life that such a condition might exist.

\section{Survey of cases}

On the whole the literature is very discouraging as regards the frequency with which this dreaded complication of icterus gravis occurs, and would lead to the belief that neonatal death from this disease is a relatively fortunate occurrence. That this is far from being the case is well illustrated by a survey of our own cases over the past ten years. During the years 1930 to 1939 inclusive, thirty-seven infants who fulfil the criteria required for the diagnosis of icterus gravis neonatorum were admitted to this hospital. Of these twenty, or about 54 per cent., died while in hospital, either of the disease, some associated congenital anomaly, or intercurrent infection. Of the surviving seventeen, one died at eight months of broncho-pneumonia and one at two-and-a-half years of osteomyelitis. Both of these exhibited head retraction, spasticity and marked mental retardation, the so-called syndrome of nuclear jaundice. Of the remaining fifteen children, eleven, ranging in age from six-and-a-half months to five years, have been followed. All are well and are normal physically and mentally, except that three of the group show a greenish-grey discoloration of their teeth. Another of the group, last seen at two months of age in 1933, was apparently normal at that time.

From these figures it is seen that approximately 46 per cent. survived the disease icterus gravis, in addition to which it may be accepted that at least 65 per cent. of those who survive do not develop ' kernikterus'. It can also be assumed that this figure may be slightly higher when the remaining members of the group are located.

Previous to January, 1935, the only form of treatment was repeated blood transfusion. At this time calcium gluconate was added and the following year intra-muscular liver extract. In an effort to evaluate the various combinations of treatment, the cases are divided into five groups (table 1). From this it is seen that those infants who had the advantage of calcium and liver in addition to transfusion comprise the largest number of recoveries.

Treatment consists primarily in early and frequent blood transfusions. They do not appear to arrest the haemolysis, but rather to tide the infant over a period of severe anaemia until the haemolytic process ceases spontaneously. It 
is our practice to transfuse as often as is necessary to maintain the haemoglobin above 60 per cent. Glucose may be given parenterally to protect the damaged liver cells.

TABLE 1

RESULTS OF VARIOUS FORMS OF TREATMENT IN 37 CASES OF ICTERUS GRAVIS NEONATORUM, 1930-39

\begin{tabular}{|c|c|c|c|c|c|}
\hline & $\begin{array}{l}\text { NO TREAT- } \\
\text { MENT; DIED } \\
\text { SHORTLY } \\
\text { AFTER } \\
\text { ADMISSION }\end{array}$ & $\begin{array}{l}\text { TRANSFUSIONS } \\
\text { ONLY }\end{array}$ & $\begin{array}{l}\text { TRANSFUSIONS } \\
\text { AND LIVER }\end{array}$ & $\begin{array}{l}\text { TRANSFUSIONS } \\
\text { AND CALCIUM }\end{array}$ & $\begin{array}{l}\text { TRANSFUSIONS, } \\
\text { LIVER AND } \\
\text { CALCIUM }\end{array}$ \\
\hline $\begin{array}{l}\text { Discharged from } \\
\text { hospital, cured } \\
\text { or improved. }\end{array}$ & 0 & 4 & 2 & 1 & 10 \\
\hline Died .. & 4 & 12 & 0 & 2 & 2 \\
\hline
\end{tabular}

Because, theoretically, bilirubin is adsorbed by the calcium of the blood, it is the custom at the Hospital for Sick Children, Toronto, to increase the available calcium by the intravenous administration of 10 c.c. of a 10 per cent. solution of calcium gluconate at the time of the first two transfusions. It is hoped by this means to prevent the excess of bile pigment from staining the vital tissues, especially the nuclear masses of the brain. Liver extract in doses of 1 to 2 c.c. ( 20 to 40 grammes) daily, is given intramuscularly for ten to fourteen days. Its value is doubtful.

The hyperplastic anaemia stage lasts as a rule from two to three weeks and is followed by an aplastic or hypoplastic stage lasting from four to six weeks. During this latter period cerophyll, in doses of four to six teaspoons, added to the daily feeding has a definite therapeutic value.

\section{Conclusions}

1. Icterus gravis neonatorum with erythroblastosis is a definite clinical entity with characteristic syndrome, blood picture and pathology.

2. Although our series is small, it would seem that the incidence of basal nuclear jaundice as a late result of the disease has been over-estimated.

3 . In evaluating the results of therapy, it would appear that a combination of repeated transfusions, intravenous calcium gluconate and intramuscular liver results in the greatest number of uncomplicated recoveries.

\section{REFERENCE}

Blackfan, K. D., Diamond, L. K., and Baty, J. M. (1932). J. Pediat., 1, 269. 